\title{
Chromosome Manipulation for Plant Breeding Purposes
}

\section{Pilar Prieto}

Plant Breeding Department, Institute for Sustainable Agriculture, Agencia Estatal Consejo Superior de Investigaciones Científicas (CSIC), Alameda del Obispo s/n, Apartado 4084, 14080 Córdoba, Spain; pilar.prieto@ias.csic.es; Tel.: +34-957-499-293

Received: 27 October 2020; Accepted: 29 October 2020; Published: 2 November 2020

\begin{abstract}
The transfer of genetic variability from related species into crops has been a main objective for decades in breeding programs. Breeders have used interspecific genetic crosses and alien introgression lines to achieve this goal, but the success is always dependent on the interspecific chromosome associations between the alien chromosomes and those from the crop during early meiosis. In this Special Issue, the strength of chromosome manipulation in a breeding framework is revealed through research and review papers that combine molecular markers, cytogenetics tools and other traditional breeding techniques. The papers and reviews included in this Special Issue "Chromosome manipulation for plant breeding purposes" describe the development and/or characterization of new plant material carrying desirable traits and the study of chromosome associations and recombination during meiosis. New tools to facilitate the transfer of desired traits from a donor species into a crop can be developed by expanding the knowledge of chromosome associations during meiosis.
\end{abstract}

Keywords: meiosis; chromosome engineering; chromosome pairing; non-homologous recombination; cytogenetics; alien chromosome; polyploidy; aneuploidy

\section{Introduction}

The capacity to exploit the potential of wild relatives carrying beneficial traits is a key goal in breeding programs. However, it depends on the opportunity of the chromosomes from the crop and the wild species in interspecific crosses to recognize, associate and undergo crossover formation during meiosis, the cellular process responsible for producing gametes carrying half the genetic content of the parent cells. Unfortunately, in most of the cases, a barrier prevents successful hybridization between the wild and the crop chromosomes. Some other approaches, such as radiation and gametocidal genes, have been used to transfer resistance genes or chromosomal segments with desirable genes from related species into a crop such as wheat. Unluckily, both approaches generate arbitrary chromosome breaks and fusion and most of the translocations occur between non-homologous chromosomes, generating deficiencies or genetic duplications that are not compensated, and, therefore, do not have interest as tools for breeding. It seems interesting to develop chromosome manipulation methods affecting homologous recombination to produce genetic introgressions that can be genetically equilibrated and transmitted to the descendance. Understanding the mechanisms controlling chromosome associations during meiosis are, therefore, of great interest in plant breeding. Examining how chromosomes recognize, associate in pairs, synapse and recombine, which are prerequisites for the balanced segregation of half-bivalents during meiosis, will allow chromosome manipulation to introduce genetic variability from related species into a crop.

Several genetic stocks such as interspecific hybrids, natural and synthetic polyploids and introgression lines derived from allopolyploids, among others, can be powerful tools to transfer genetic traits from one species into another and for meiosis studies. For example, an extra pair of 
alien chromosomes in the full genome of a crop species has been often used as a first step in breeding programs to introduce genetic variation from the secondary gene pool. Moreover, such introgression lines are also essential in the study of interspecific genetic interactions, in the chromosomal location of genetic markers and in the study of chromosome structure and behaviour in somatic and meiotic cells.

Through several research papers and reviews, this Special Issue of Agronomy describes the use of chromosome introgressions as an excellent tool to transfer several characters mainly into cereal crops such as wheat, rye and triticale and their use in meiosis studies with the aim of promoting interspecific chromosome rearrangements and recombination. Other genetic stocks are also studied in this Special Issue for plant breeding purposes.

\section{Chromosome Manipulation within the Triticeae Tribe}

The Triticeae tribe is included in the Poaceae (Gramineae) family and contains grain crops of world-wide economic importance such as wheat (Triticum), barley (Hordeum) and rye (Secale), as well as a profuse number of grasses used for animal feed or rangeland protection. Bread wheat is one of the most important crops in the world. Breeders have been using related species as genetic donors with the aim of widening the genetic basis of a crop and getting, for example, wheat cultivars better adapted to specific agro-climatic conditions or carrying resistance to pests. Hordeum chilense, a perennial diploid wild barley that has an extremely high potential for wheat breeding, has been used to develop wheat- $H$. chilense chromosome $2 \mathrm{H}^{\mathrm{ch}}$ introgression lines to be used for improving grain quality [1]. Chromosome $2 \mathrm{H}^{\text {ch }}$ carries endosperm carotenoid-related genes, which can contribute to improve seed carotenoid content in wheat. These authors have used a wheat disomic addition line carrying $2 \mathrm{C}^{\mathrm{C}}$ chromosome from Aegilops cylindrica Host. to induce chromosome reorganizations between $2 \mathrm{H}^{\mathrm{ch}}$ and wheat chromosomes. New wheat- $H$. chilense recombinants that can be useful for studying the effect of chromosome $2 \mathrm{H}^{\text {ch }}$ in grain quality have been identified using in situ hybridisation and molecular markers.

Hordeum chilense has been also used to evaluate the variability for the $W x$ gene that encodes a waxy protein (a granule-bound starch synthase I), responsible for amylose synthesis [2]. Authors have located this $W x$ gene on the long arm of $7 \mathrm{H}^{\text {ch }}$ chromosome and have identified two different alleles of this gene in $H$. chilense. This genetic variability could be transferred into wheat by introgressing $7 \mathrm{H}^{\text {ch }} \mathrm{L}$ chromosome segments, as the current variability present in wheat cultivars is not very wide.

Several genes contribute to the bread-making quality in wheat such as glutenins, the wheat bread-making $(w b m)$ gene and the presence of the 1BL.1RS translocation, among others. Little is known about the origin of the $w b m$ gene and its genomic organization [3]. These authors examined $w b m$ evolution and demonstrated the location of this gene in 7AL chromosome. Thus, it was possible to identify triticale lines carrying $w b m$ to be used in the improvement of the bread-making quality of this crop.

Chromosome introgressions are also used to transfer resistance against pathogens. In triticale ( $\times$ Triticosecale Wittmack) new pathogens have evolved, moving from wheat and rye into triticale due to the increment of the harvested area. A screening of robertsonian translocations in the progeny of triticale lines carrying monosomic substitutions of Aegiops kotschyi chromosome $2 \mathrm{~S}^{\mathrm{k}}(2 \mathrm{R})$ was carried out using in situ hybridisation [4]. Plants carrying the robertsonian translocation were also checked using molecular markers for the presence of the Lr54 and Yr37 leaf rust and stripe rust resistance genes. It is clear that in situ hybridisation is a cytological procedure that allows the identification of alien chromatin in a given species and it is widely used in breeding programs based on marker-assisted selection.

Introgression lines carrying univalent chromosomes can also be used to generate chromosome rearrangements between the added alien chromosome and the ones from the crop species. Univalent chromosomes can suffer misdivission, chromosome breaks or interspecific recombination with chromosomes from the crop species during meiosis and therefore, series of introgression lines including deleted chromosomes of an alien species can be developed to contribute to the localization of desirable genes. This has been the methodology used to obtain rye introgressions in wheat carrying 
several deletions of chromosome $5 \mathrm{R}^{\mathrm{ku}}$ from S. cereale L. Kustro [5]. in situ hybridisation and molecular markers allowed the characterisation of the different deletions of $5 \mathrm{R}^{\mathrm{ku}}$ chromosome and the stripe rust resistant genes location to a region of the long arm of $5 R^{\mathrm{ku}}$ chromosome.

Fluorescence in situ hybridisation has also been used to visualize the chromosomal localization of repetitive sequences that might contribute to chromosome identification. For example, the identification of a novel mini-satellite repeat (Ta-3A1) in wheat has allowed a phylogenetic analysis between wheat and some related species [6]. Non-denaturing in situ hybridisation (ND-FISH) was conducted using the Ta-3A1 sequence as a probe on chromosome preparations of wheat and in a long number of related wild and cultivated species, included in the tribe Triticeae dumort, as well as in other wheat-alien species amphiploids. The combination of cytogenetics tools and genomic research on repetitive sequences, including the mini-satellite, can contribute to wheat breeding activities, including chromosome manipulation and engineering.

The stability all these chromosome rearrangements are dependent on interspecific chromosome associations and recombination events, which are required during meiosis between the alien chromosomes and those from the crop, to obtain stable chromosome introgressions carrying useful agronomic traits. Thus, the study of chromosome associations during meiosis in general, and chromosome recombination in particular, is of great interest in the framework of chromosome manipulation for plant breeding purposes. A deep review about meiotic recombination within the Triticeae tribe, and especially those features concerning polyploidy wheat, is included in this Special Issue. The significance of chromosome rearrangements on meiotic recombination and the importance of recombination in the framework of chromosome manipulation for breeding purposes is also reviewed [7].

\section{Chromosome Engineering in other Plant Species}

A chromosomal study of other crop species such as coffee (Coffea arabica L.) and cacao (Theobroma cacao L.), which are of great importance especially for several national economies in Africa, Latin America and Asia, has been included in this Special Issue. Papaya is also a valuable tropical crop for its high nutritional value. Minor tropical crops such as coffee, cacao and papaya do not easily benefit from public and private breeding programs, in contrast to the huge amount of money dedicated to improving major crops, such as wheat. In addition, coffee and cacao are suffering the effect of climate change, accelerating the loss of genetic diversity for future plant breeding programs. Thus, better adapted crops are necessary to facilitate their adaptation to climate change and recombination plays a key role in conventional breeding programs to improve modern varieties by increasing their variability using related species as genetic donors [8]. Other possibilities for chromosome engineering to increase recombination and crossover formation to facilitate the introgression of desirable traits in these tropical crops are also reviewed [8].

Meiwa kumquat (Fortunella crassifolia Swingle) is a lesser-known species of kumquat, which was originally classified as Citrus japonica, citrus of Japan, until received its own unique genus distinction. A combination of flow cytometry and a microscopy analysis has been performed to clarify the ploidy level of a $2 x+4 x$ ploidy chimera of $F$. crassifolia which can be used for breeding purposes [9]. Authors also pointed that this chimera can be used for triploid breeding, where seedless fruits can be expected.

Funding: Experimental work in the Crops Biotechnology Group of P.P. is supported by the Spanish Ministerio de Ciencia e Innovación and The European Regional Development Fund (FEDER) from the European Union.

Conflicts of Interest: The author declares no conflict of interest. 


\section{References}

1. Palomino, C.; Cabrera, A. Development of wheat-Hordeum chilense chromosome $2 \mathrm{H}^{\mathrm{ch}}$ introgression lines potentially useful for improving grain quality traits. Agronomy 2019, 9, 493. [CrossRef]

2. Álvarez, J.B.; Castellano, L.; Recio, R.; Cabrera, A. Wx gene in Hordeum chilense: Chromosomal location and characterisation of the allelic variation in the two main ecotypes of the species. Agronomy 2019, 9, 261. [CrossRef]

3. Kirov, I.; Pirsikov, A.; Milyukova, N.; Dudnikov, M.; Kolenkov, M.; Gruzdev, I.; Siksin, S.; Khrustaleva, L.; Karlov, G.; Soloviev, A. Analysis of wheat bread-making gene (wbm) evolution and occurrence in triticale collection reveal origin via interspecific introgression into chromosome 7AL. Agronomy 2019, 9, 854. [CrossRef]

4. Ulaszewski, W.; Belter, J.; Wisniewska, A.; Szymczak, J.; Skowronska, J.; Phillips, D.; Kwiatek, M.T. Recovery of 2R.2Sk Triticale-Aegilops kotschyi robertsonian chromosome translocations. Agronomy 2019, 9, 646. [CrossRef]

5. Xi, W.; Tang, Z.; Luo, J.; Fu, S. Physical location of new stripe rust resistance gene(s) and PCR-based markers on rye (Secale cereale L.) chromosome 5 using 5R dissection lines. Agronomy 2019, 9, 498. [CrossRef]

6. Lang, T.; Li, G.; Yu, Z.; Ma, J.; Chen, Q.; Yang, E.; Yang, Z. Genome-wide distribution of novel Ta-3A1 mini-satellite repeats and its use for chromosome identification in wheat and related species. Agronomy 2019, 9, 60. [CrossRef]

7. Naranjo, T. The effect of chromosome structure upon meiotic homologous and homoeologous recombinations in Triticeae. Agronomy 2019, 9, 552. [CrossRef]

8. Bolaños-Villegas, P. Chromosome engineering in tropical cash crops. Agronomy 2020, 10, 122. [CrossRef]

9. Nukaya, T.; Sudo, M.; Yahata, M.; Ohta, T.; Tominaga, A.; Mukai, H.; Yasuda, K.; Kunitake, H. The confirmation of a ploidy periclinal chimera of the Meiwa Kumquat (Fortunella crassifolia Swingle) induced by colchicine treatment to nucellar embryos and its morphological characteristics. Agronomy 2019, 9, 562. [CrossRef]

Publisher's Note: MDPI stays neutral with regard to jurisdictional claims in published maps and institutional affiliations.

(C) 2020 by the author. Licensee MDPI, Basel, Switzerland. This article is an open access article distributed under the terms and conditions of the Creative Commons Attribution (CC BY) license (http://creativecommons.org/licenses/by/4.0/). 